\title{
(3) IEB
}

Institut

d'Economia

de Barcelona

\section{Document de treball de l'IEB 2013/25}

THE FIGHT AGAINST CARTELS: A TRANSATLANTIC PERSPECTIVE

Emilie Dargaud, Andrea Mantovani, Carlo Reggiani 
THE FIGHT AGAINST CARTELS: A TRANSATLANTIC PERSPECTIVE

Emilie Dargaud, Andrea Mantovani, Carlo Reggiani

The Barcelona Institute of Economics (IEB) is a research centre at the University of Barcelona which specializes in the field of applied economics. Through the IEBFoundation, several private institutions (Applus, Abertis, Ajuntament de Barcelona, Diputació de Barcelona, Gas Natural and La Caixa) support several research programs.

Postal Address:

Institut d'Economia de Barcelona

Facultat d'Economia i Empresa

Universitat de Barcelona

C/ Tinent Coronel Valenzuela, 1-11

(08034) Barcelona, Spain

Tel.: + 34934034646

Fax: + 34934039832

ieb@ub.edu

http://www.ieb.ub.edu

The IEB working papers represent ongoing research that is circulated to encourage discussion and has not undergone a peer review process. Any opinions expressed here are those of the author(s) and not those of IEB. 


\title{
THE FIGHT AGAINST CARTELS: A TRANSATLANTIC PERSPECTIVE *
}

\author{
Emilie Dargaud, Andrea Mantovani, Carlo Reggiani
}

\begin{abstract}
The fight against cartels is a priority for antitrust authorities on both sides of the Atlantic. What differs between the EU and the US is not the basic toolkit for achieving deterrence, but to whom it is targeted. In the EU, pecuniary sanctions against the firm are the only instruments available to the Commission, while in the US criminal sanctions are also widely employed. The aim of this paper is to compare two different types of fines levied on managerial firms when they collude. We consider a profit based fine as opposed to a delegation based fine, with the latter targeting the manager in a more direct way. Under the assumption of revenue equivalence, we find that the delegation based fine, although distortive, is more effective in deterring cartels than the profit based one. When evaluating social welfare, a trade-off between deterrence and output distortion can arise. However, if the antitrust authority focuses on consumer surplus, then the delegation based fine is to be preferred.
\end{abstract}

JEL Codes: K21, L44, K42, L21

Keywords: Cartel policy, managerial firms, collusion.

Emilie Dargaud

University of Lyon \&

CNRS, GATE

Lyon St Etienne, 93

Chemin des Mouilles

F-69130, Ecully, France

E-mail: dargaud@gate.cnrs.fr

\author{
Andrea Mantovani \\ Department of Economics, \\ University of Bologna \& IEB \\ Strada Maggiore 45 \\ 40125 Bologna, Italy \\ E-mail: a.mantovani@unibo.it
}

Carlo Reggiani

School of Social Sciences-

Economics

University of Manchester

Manchester M13 9PL, United

Kingdom

E-mail: carlo.reggiani@manchester.ac.uk

\footnotetext{
* We would like to thank Antoine Chapsal, Xeni Dassiou, Luca Lambertini, Piercarlo Zanchettin and participants in the CCRP Workshop, the MaCCI Conference 2013, and the Seventh International Conference on Game Theory and Management (Saint Petersburg, 2013) for helpful comments and discussion. The usual disclaimer applies.
} 


\section{Introduction}

The past decade has witnessed an increase in price-fixing, market-sharing and bidrigging cartel behaviour across the two sides of the Atlantic. As a consequence, the fight against cartels evolved from transnational to 'transatlantic', requiring unprecedented efforts and collaboration between US and EU antitrust authorities. ${ }^{1}$ The most evident example is probably the gradual convergence of their corporate leniency programs, with the EU revisiting its legislation in 2002 on the basis of the US experience. Although some differences still remain, scholars and policy makers agree that the socalled "leniency revolution" (Spagnolo, 2008) brought forth a very effective tool for uncovering existing cartels on both sides of the Atlantic.

A similar convergence process did not occur in the sanctionatory procedure. The respective legal and enforcement regimes remain quite different in the US in comparison to the EU. Cartels are commonly treated as criminal offences in the US, where anticompetitive activities are sanctioned with fines of up to USD 1 million and/or with a sentence of up to ten years of imprisonment. ${ }^{2}$ The situation is however different in the EU, where the violation of Art. 101 of the TFEU is generally not interpreted as a criminal offence. The imposition of pecuniary sanctions against cartel members is therefore the only instrument at the disposal of the Commission to use. ${ }^{3}$

In light of this, would it be in the best interest of the EU to also adopt criminal sanctions in order to crack down on cartel members? First, one should consider whether or not such criminalisation is feasible at the EU level. Recent interpretations under the current Treaty of Lisbon have stirred controversy, and the general opinion is that undertaking such a reform would require a long and costly process. ${ }^{4}$ Second,

\footnotetext{
${ }^{1}$ The European Commission, the Department of Justice and the Federal Trade Commission cooperate together primarily on the basis of the 1991 Cooperation Agreement and of the 1998 "Positive Comity Agreement". The latter is also concerned with the exchange of information in cartel activities.

${ }^{2}$ The current level of sanctions are defined by the Antitrust Criminal Penalty Enhancement and Reform Act of 2004. In the ten year period 2003-2012, the US Courts sentenced 255 people to a total of 176,926 days of imprisonment. Statistics available on the US Department of Justice's website, <www.justice.gov/atr/public/workload-statistics.html>, accessed on 16 June 2013.

${ }^{3}$ The position held by the EU regarding the definition of criminal offences and sanctions is not completely clear. At the moment, national authorities in ten Member States can impose criminal sanctions, including imprisonment, against individuals involved in cartels (Massey, 2004, e.g., explains the Irish case). Their use is, however, very limited.

${ }^{4}$ Reindl (2006), for example, argues that the Commission would have to increase its standard of proof in order to prove culpability. This could limit the number of cases that can be investigated.
} 
many commentators reckon that such criminalisation, even if possible, would not be desirable in the socio-economic and cultural context of the EU. ${ }^{5}$

On these grounds, the purpose of this paper is not to provide a holistic comparison between two sanctionatory approaches influenced by two inherently different worldviews. Rather, we attempt to model, in a stylised way, the "punishing-the-firm versus punishing-the-person" controversy and better understand its economic effects. To this aim, we consider a model of repeated Cournot competition with managerial firms and study how the sustainability of collusion can be affected by different types of sanctions.

In particular, a representative antitrust authority has to decide between two types of penalties aimed at deterring cartel formation. The first type of penalty targets a firm's profit and it is the most commonly used instrument in the literature. The second type targets instead the manager's terms of contract and, in particular, its delegated powers. Although this stylised modelling device does not fully capture the idea of criminal sanction such as imprisonment, it does however constitute a first attempt to represent a measure intended to criminalise the collusive behaviour of managers. This represents the main novelty of the paper.

First, we demonstrate that both types of fines reduce the interval region where collusion can be sustained, although their effectiveness is dampened by delegation intensity. We then evaluate their relative performance. The main result is that, under a revenue equivalence assumption, a delegation based fine proves more effective in deterring collusion than a profit based fine.

We also consider welfare implications. The delegation based fine has a distortionary effect on the output level and may consequently have a negative effect on total surplus. This reveals the existence of a potential conflict between ex ante cartel deterrence and ex post output provision. In order to navigate such a trade-off, we compare the expected welfare generated by the two fines. The solution is straightforward if we limit our attention to consumer surplus, as we show that the delegation based fine is always preferred by consumers as well. However, when we consider total expected welfare, then the trade-off may reappear, as the choice between the two instruments depends on the combined effect of the delegation intensity and the amount of the fine.

\footnotetext{
${ }^{5}$ Khan (2012) provides a very interesting and thorough discussion on this issue. See also Buccirossi and Spagnolo (2007), who evaluate benefits and costs of imprisonment in terms of cartel deterrence.
} 
Hence, under the basic assumptions and limitations of the model, our paper indicates that an antitrust authority mainly concerned with consumer protection should punish managers more directly. On the contrary, if the target is the interest of society at large, then ex ante and ex post efficiency can be restored only under certain specific conditions, and a delegation based fine is not always the best solution.

\section{Related Literature}

Since the pioneering work of Becker (1968), economists have developed an extensive literature related to "optimal sanctions". ${ }^{6}$ Sanctions should not only seek to punish detected cartels (ex-post efficiency) but also to discourage firms to engage in such illegal practices (ex-ante efficiency). We are mainly concerned with the deterrence effect of a sanction. Souam (2001) contributes to this line of research in that he considers the effect of revenue based fines as opposed to damage based fines. In his paper, however, what matters is how the fine is computed, not who should pay it.

A number of works have addressed the issue of imprisonment as a punishment for cartels and price fixers, the first and best known probably being Werden and Simon (1987). Gallo et al. (1994) present empirical evidence on the criminal punishment enforced in the USA and they compare it with the theoretical optimum. In a related paper, Craycraft et al. (1997) evaluate the fine levied in relation to the firm's ability to repay and take into consideration the value of the time spent in prison. Buccirossi and Spagnolo (2007) present simulation evidence to question the role of imprisonment in presence of leniency programs and whistleblowing. As underlined, our paper does not directly address imprisonment as a punishment for managers; however, we directly address the issue of punishing mainly the firm or the managers and to do so, we model a managerial firm. ${ }^{7}$

Cartels have received great deal of attention in the literature in recent years, mainly due to two factors. On the one hand, the activity of cartels is very common despite the efforts of antitrust authorities; on the other hand, the success of deterrence has been increased in the last decade mainly due to leniency programs. The seminal

\footnotetext{
${ }^{6}$ See, for example, Besanko and Spulber (1989), and more recent contributions as Buccirossi and Spagnolo (2007) and Allain et al. (2011), inter alii.

${ }^{7}$ In general, the use of criminal sanctions faced several opponents particularly in Europe where cartel practices do not produce strong moral disapproval. Wils (2002 and 2005) analyses the individual sanctions and imprisonment with particular reference to the EU situation.
} 
paper by Motta and Polo (2003) has been followed by contributions that extend and discuss the use of leniency programs (Spagnolo, 2004; Aubert et al., 2006; Chen and Rey, 2012). Aubert et al. (2006) focus on the different impact of reduced fines and positive rewards and find that rewarding individuals is more effective in deterring collusion. Although their paper is related to ours, the objective is very different: we do not focus on leniency and whistleblowing but on deterrence through fines, targeted either to the firms or to the managers.

The majority of the literature on cartels and collusion treats the firm as a profitmaximising decision maker, thereby deriving key insights on cartel stability and behaviour from a profit-maximising perspective. However, cartels often involve firms having separated ownership and control in such a way that the incentives of the key decision maker (CEO, manager) may not be fully aligned with those of the profitmaximising shareholders. A manager's objective depends on the structure of the incentives that the owner designs in order to motivate him. Owners often index managerial compensation to profit, sales and many other variables. The split between ownership and control can lead to non-profit-maximising behaviour particularly if managers are interested in maximising their own utility. For example, managers' reputation often relates to the size of the company and their decisions may be driven by "empire building" motivations rather than maximising the value of the firm for its shareholders (Baumol, 1958). The corporate governance factors can have a key impact on the operation of cartels. ${ }^{8}$

Our approach follows Vickers (1985) and Fershtman and Judd (1987): the owners of the firms can delegate some decisional power to their managers that have the objective of maximising a combination of profit and output, assumed to be a proxy of the size of the firm. Delegation affects the best responses of firms and impacts the strategic outcome of the game. This allows us to tackle the main research question in a relatively simple way. On top of that, the assumption of managerial firms reflects the observation that this is the nature of the majority of firms that raise the attention of antitrust authorities. ${ }^{9}$

\footnotetext{
${ }^{8}$ See Spagnolo (2005) or Buccirossi and Spagnolo (2007) for a research agenda on corporate governance factors and collusion.

${ }^{9}$ Recent cases of cartels operating in relatively similar sectors in the EU (TV and computer monitor tubes) and in the US (LCD producers) clearly witness this. The decision of the EC involved fines of about $€ 1.4$ billion on seven of the participating firms; the DOJ decision, on the other hand, fined for about $\$ 1.39$ billion eight firms and inflicted a jail sentence to two senior executives of the Taiwanese company AU Optronics. Besides reflecting different approaches to cartel punishment, these cases
} 
Lambertini and Trombetta (2002) consider optimal delegation when managers can collude on the product market after owners have set their incentives schemes, either collusively or not. They show that if owners collude when managers behave non-cooperatively, then collusion becomes more difficult to sustain. However, if both managers and owners can collude, the outcome depends on the level of patience of both agents and owners can "exploit" managers' patience to improve on their outcomes. Our paper assumes that delegation to managers takes place and addresses the issue of the effect of different types of fines to deter collusion.

The rest of the paper is structured as follows. In Section 2 we present the basic model and the features of the two types of fines and provides some results. Section 3 focuses on the welfare effects of different approaches to cartel deterrence. Section 4 discusses the results and concludes. All proofs are in the Appendix.

\section{Model and Analysis}

We consider a duopoly model in which firms compete à la Cournot in the final product market. The inverse demand is linear, and given by $p=a-Q$, where $Q=q_{1}+q_{2}$. The marginal cost is constant and equal to $c$ for both firms. An important feature of our model is that firms are run by managers, who maximise a combination of firm's profit $\left(\pi_{i}\right)$ and sales $\left(q_{i}\right)$. This is captured by the following objective function (Vickers, 1985; Lambertini and Trombetta, 2002):

$$
m_{i}=\pi_{i}+\theta_{i} q_{i}, \quad i=1,2,
$$

where $\theta_{i}$ is the relevance of sales and represents a measure of delegation. ${ }^{10}$ We assume that the delegation parameter is given and, as firms are symmetric, then incentives schemes are such that $\theta_{1}=\theta_{2}=\theta$.

For simplicity of notation and without loss of generality, we set $A=a-c$. The managers' objective function can be rewritten as follows:

$$
m_{i}=(A-Q+\theta) q_{i}, \quad i=1,2,
$$

and $A$ is high enough to guarantee that all quantities and profits are non-negative.

show how the corporate structure of the vast majority of the firms involved managers who have been delegated decisions by its owners or shareholders.

${ }^{10}$ When they maximise $m_{i}$, managers also maximise their compensation as their remuneration is proportional to $m_{i}$. 
The basic stage game is repeated infinitely many times. In each stage, managers decide whether to play non-cooperatively, or to produce the collusive output. As a result, the payoffs for each manager are denoted respectively as $m_{i}^{N}, m_{i}^{C}$, and $m_{i}^{D}$, where $N$ indicates the Cournot-Nash equilibrium, $C$ the collusive equilibrium, and $D$ the deviation from collusion, when the rival sticks to its cartel output level. To simplify notation, by using symmetry, we remove subscript $i$. In absence of fines, it is immediate to verify that $m^{N}=(A+\theta)^{2} / 9, m^{C}=(A+\theta)^{2} / 8$ and $m^{D}=9(A+\theta)^{2} / 64$.

Collusion is sustained through a grim trigger strategy (Friedman, 1971): if one firm deviates from the collusive agreement, it is punished by reverting to Cournot competition forever. Let $\alpha_{i} \in[0,1]$ define manager $i$ 's individual discount factor. We assume that players' intertemporal preferences are pairwise symmetric, hence $\alpha_{1}=\alpha_{2}=\alpha$.

Standard derivations show that managers form a sustainable cartel when their discount factor is sufficiently high, i.e. $\alpha \geq \frac{m^{D}-m^{C}}{m^{D}-m^{N}}$. In the present setting, this implies:

$$
\alpha \geq \frac{9}{17} \equiv \alpha^{*}
$$

which is the same threshold level than in the game without delegation. ${ }^{11}$ This represents our benchmark case.

For future reference, the collusive per-firm outcome is $q^{C}=(A+\theta) / 4$, and the Cournot-Nash one is $q^{N}=(A+\theta) / 3$. Moreover, firms' symmetric net profits are respectively given by $\pi^{C}=[(A-\theta)(A+\theta)] / 8$ and $\pi^{N}=[(A-2 \theta)(A+\theta)] / 9$. We assume that $A \geq 2 \theta$ to ensure the non-negativity of such profits.

\section{The fight against cartels: two types of fines}

In our model, the antitrust authority can use two types of fines to deter cartel formation. The first type targets the profits of the firm, while the second directly affects the manager's delegation contract. We suppose that a cartel agreement requires some communication between managers, therefore generating tangible evidence. However, consistently with the literature (Rey, 2003; Motta and Polo, 2003; Aubert et al., 2006; Avramovich, 2010), we assume that the evidence disappears at the end of each period and therefore firms are not sanctioned in case of deviation.

\footnotetext{
${ }^{11}$ For more details, see Lambertini and Trombetta (2002), p. 362.
} 


\subsection{The profit based fine}

The antitrust authority is supposed to detect the collusive behaviour between managers with probability $\rho .{ }^{12}$ When this happens, it launches an investigation leading to a successful prosecution of the cartel. A total fine $F$ is imposed implying that each firm pays $F / 2$. Type I errors (firms which do not collude but are still prosecuted) are assumed not to occur, whereas Type II errors (colluding firms are not fined) do.

Under these assumptions, the colluding managers jointly maximise:

$$
M=(A-Q+\theta) Q-\rho F .
$$

Taking the first-order condition (FOC) and imposing symmetry, we find that each firm still produces $q^{C}=(A+\theta) / 4$, as the expected fine $\rho F$ enters as a fixed cost. This implies that the strategic response by the cheating player also remains the same, and so does its final payoff, as we assumed that firms are not punished in case of deviation. Then, $m^{D}=9(A+\theta)^{2} / 64$. As Cournot-Nash profits do not depend on the fine, we obtain again $m^{N}=(A+\theta)^{2} / 9$.

The only difference w.r.t. the benchmark case is represented by the expected payoff in case of collusion, which results in $m_{P}^{C}=(A+\theta)^{2} / 8-\rho F / 2$, where subscript $P$ indicates the change brought by the profit based fine.

As the incentive to form a cartel appears in presence of a prisoners' dilemma (i.e. individual collusive payoff must be higher than Cournot payoff), we assume that:

$$
m_{P}^{C} \geq m^{N} \Longleftrightarrow \rho F \leq \bar{T}=\frac{(A+\theta)^{2}}{36},
$$

with $\bar{T}$ being the the maximum level of the profit based fine. ${ }^{13}$

Under condition (5), managers can sustain the collusive agreement over time if and only if their discount factor satisfies the following condition:

$$
\alpha \geq \frac{9}{17}\left[1+\frac{32 \rho F}{(A+\theta)^{2}}\right] \equiv \alpha_{P}
$$

The above expression showcases the most important features of the profit based fine. Obviously, the higher the expected fine, the more difficult is to collude. Interestingly, for any given level of $\rho F$, notice that $\alpha_{P}$ decreases in $\theta$, as the manager's

\footnotetext{
${ }^{12}$ The exogeneity of the parameter $\rho$ eliminates several potential effects of the antitrust policy. If $\rho$ depended on the firms' prices (or quantities), then the cartel would adopt complex price patterns (Harrington, 2004 and 2005; Harrington and Chen, 2006).

${ }^{13}$ This, a fortiori, also guarantees that cartel payoffs are positive.
} 
payoff positively depends on the delegation parameter. In other words, to achieve the same level of deterrence $\left(\alpha_{P}\right)$ the expected fine needs to be bigger, the more powers are delegated to the managers $(\theta)$.

Obviously, in absence of the antitrust policy $(\rho F=0), \alpha_{P}$ would coincide with the benchmark the threshold value $\alpha^{*}=9 / 17$. In the opposite scenario, $\alpha_{P}=1$ when $\rho F=\bar{T}$, and the collusive agreement is not an option for managers.

\subsection{The delegation based fine}

If managers are delegated decisions on behalf of the owners, then the antitrust authority may decide to punish them in a more direct way than by sanctioning the firm. In other words, the authority may target the manager's delegation parameter $\theta$. In our model, this implies that a fine $f$ is levied on $\theta$ when collusion is detected, and this occurs with probability $\rho$. In this case, the colluding managers jointly maximise:

$$
M=[A-Q+(\theta-\rho f)] Q,
$$

where $\rho f \cdot Q$ indicates the total amount of the expected delegation based fine. ${ }^{14}$

Taking FOC and using symmetry, the individual collusive outcome is given by $q_{D}^{C}=(A+\theta-\rho f) / 4$, where additional subscript $D$ indicates that collusive output levels change when a delegation based fine is levied. Hence:

Remark 1 Collusive output is affected by the delegation based fine. In particular, one can immediately notice that $q_{D}^{C}<q^{C}$.

The expected fine is now taken into account by the colluding managers in their maximisation process, and it induces a reduction in the output level. This will have important consequences in terms of social welfare, as we will discuss in the next section. The corresponding payoff of a manager participating in the cartel can be easily obtained, and it amounts to $m_{D}^{C}=(A+\theta-\rho f)^{2} / 8$.

Interestingly, following Remark 1 , the strategic response of the deviating player now includes the expected fine. This in turn affects the deviation payoff, which amounts to $m_{D}^{D}=[3(A+\theta)+\rho f]^{2} / 64$. As a consequence:

\footnotetext{
${ }^{14}$ The expected fine can be interpreted as a monetary reduction of the managers' payment or an expected utility loss deriving from the risk of being caught colluding. Although we underlined that our model does not explicitly model criminal sanctions, in a more general interpretation the delegation based fine can be thought as a reduced form that captures the expected loss of reputation, benefits and other damages incurred by a guilty manager.
} 
Remark 2 The delegation based fine increases the incentive to deviate from the collusive outcome, as $m_{D}^{D}>m^{D}$.

A complete evaluation of the respective effectiveness of the two policy instruments will be performed in the next section. However, Remark 2 already unveils one of the point of strength of the delegation based fine vis-à-vis the profit based fine: deviating from a collusive agreement becomes more profitable for the manager.

As Cournot-Nash payoffs are not affected by the fine, we can now compute the threshold value of the discount factor which sustains collusion under the delegation based fine. We need to ensure that the individual collusive payoff is still higher than Cournot one. This requires:

$$
m_{D}^{C} \geq m^{N} \Longleftrightarrow \rho f \leq \bar{t}=\frac{(A+\theta)(3-2 \sqrt{2})}{3} .
$$

We assume that the condition expressed in (8) holds throughout the paper.

Under condition (8), managers have an incentive to form a cartel if and only if:

$$
\alpha \geq \frac{9}{17}\left[1+\frac{64 \rho f[5(A+\theta)-2 \rho f]}{(A+\theta+3 \rho f)[17(A+\theta)+3 \rho f]}\right] \equiv \alpha_{D}
$$

Similarly to the previous case, the higher the expected fine, the more difficult is to collude. Moreover, for any given level of the expected fine, $\alpha_{D}$ also decreases in $\theta$. Finally, it is immediate to verify that $\alpha_{D} \equiv \alpha^{*}$ when the expected fine tends towards zero, and that $\alpha_{D}=1$ when $\rho f=\bar{t}$.

\subsection{Profit based and delegation based fine: a comparison}

The two types of fines can be compared and conditions can be found for which one is more effective than the other in deterring collusion. The following holds:

Proposition 1 Suppose $\rho F \leq \bar{T}$ and $\rho f \leq \bar{t}$, then a profit based fine is more effective in deterring collusion if and only if:

$$
\rho F>\widetilde{T}=\frac{2 \rho f(A+\theta)^{2}(5(A+\theta)-2 f \rho)}{(A+\theta+3 f \rho)(17(A+\theta)+3 \rho f)} .
$$

The opposite holds, obviously, when $0<\rho F<\widetilde{T}(\rho f)$. Finally, the threshold value $\widetilde{T}$ increases with $\theta$.

Proof See the Appendix. 
Proposition 1 conveys two main messages. The first one has an intuitive appeal: the instrument that prevails in deterring cartels depends on the relative intensity of the profit based fine as compared to the delegation based fine. The second one is more interesting as it pertains to the delegation mechanism. The fact that $\widetilde{T}$ increases with $\theta$ implies that a profit based lump-sum fine is more likely to deter cartels if owners retain most of the decisional power. On the contrary, a distortive fine, targeting managers more directly, is more effective when managers are delegated a high decisional power.

Finally, notice that the comparison depends on the probability of collusion being detected despite this is identical in the two settings: this is due to the fact that the delegation based fine is distortive and affects the managers' choices.

\section{Revenue equivalence}

The results in Proposition 1 are strongly affected by the possibility that the antitrust authority charges two different levels of sanctionatory fines, depending on whether it opts for the profit based fine, or for the delegation based fine. However, it would be probably more relevant for the policy maker to find out which of the two instruments performs better for a given value of the expected revenue. ${ }^{15}$

In this context, a revenue equivalence requirement implies:

$$
\rho F=\rho f \cdot 2 q_{D}^{C}
$$

Following (10), condition (5) can be re-written as:

$$
\rho f<\frac{(A+\theta)}{6}(3-\sqrt{7}) .
$$

By comparing (11) with (8), we find that the binding condition is $\bar{t}$. This already seems to indicate a superior performance of the delegation based instrument, which is more efficient in eliminating the incentive to collude. Moreover, under (10) the threshold discount factor $\alpha_{P}$ that appears in (6) can be re-expressed as:

$$
\alpha_{P}^{r e} \equiv \frac{9}{17}\left[1+\frac{16 \rho f(A+\theta)-16(\rho f)^{2}}{(A+\theta)^{2}}\right] \text {, }
$$

where superscript re indicates revenue equivalence. It follows that:

\footnotetext{
${ }^{15}$ This may especially be the case if the antitrust authority has limited resources, which are mainly generated by the fines imposed to and collected from detected cartels.
} 
Proposition 2 Under (10) and assuming $\rho f<\bar{t}$, we obtain that $\alpha_{D}>\alpha_{P}^{r e}$ : a delegation based fine is more effective than a profit based lump-sum fine in deterring cartel formation.

Proof See the Appendix.

The main message of Proposition 2 is that the delegation based fine is more effective in deterring collusion than the profit based fine. We already know that, unlike the lump sum fine, the delegation based fine makes the deviation payoffs more appealing (Remark 2), thus reducing the incentive to stick to the collusive outcome. This occurs because the best response output of the deviating manager is increased as the opponent expects to be fined and, hence, reduces its output.

In addition, the delegation based instrument, being distortive (Remark 1), has a stronger impact on manager's collusive payoff than the profit based one. Indeed, under revenue equivalence, $\left(m_{P}^{C}\right)^{r e}=\left[(A+\theta)^{2}-2 \rho f(A+\theta-\rho f)\right] / 8$. It is immediate to demonstrate that the collusive payoff is lower under the delegation based fine, as $m_{D}^{C}-\left(m_{P}^{C}\right)^{r e}=-(\rho f)^{2} / 8$.

The overall outcome of these two forces is to increase the value of the minimum discount factor that sustains collusion under the delegation based fine as compared to the profit based one.

\section{Welfare implications}

The main message to be taken from the previous section is that the delegation based fine, although distortive, is more effective in deterring cartels in comparison to a profit based fine. Based on an ex-ante reasoning, it should therefore be implemented by the antitrust authority. However, if it misses the mark, a delegation based instrument may have an ex-post negative impact on consumer surplus, as the quantity produced under collusion would shrink. The aim of this section is to explore this possible tradeoff. In doing so, we focus on the expected welfare generated by each instrument.

In our setting, cartel deterrence crucially depends on the patience of the managers. To keep our model as simple as possible, we assume that from the antitrust authority perspective there is a uniform distribution of the managers' discount factor, i.e. $\alpha \sim$ $U[0,1]$. This may be the case if the antitrust authority has no prior information about the managers that operate in the market: as a consequence, any discount factor is equally likely to be realised. 
The expected welfare can then be written as:

$$
E W=\alpha W^{N}+(1-\alpha) W^{C}
$$

where $W^{N}$ is a generic measure of welfare generated under Cournot-Nash competition, and $W^{C}$ is the one associated to the cartel. This allows us to compare the impact of the two fines on both consumer surplus and total welfare in a relatively simple way.

\subsection{Consumer surplus}

The top priority of antitrust authorities in many countries is to protect consumers interests. ${ }^{16}$ Hence, it is worth evaluating the impact on consumer surplus of the two instruments that we consider. As the demand function is linear, and given that we consider a symmetric duopoly, consumer surplus can be written as:

$$
C S=Q^{2} / 2 \equiv 2 q^{2}
$$

In the benchmark case, in which no penalty is implemented, collusion is sustainable for $\alpha>\alpha^{*}=9 / 17$. Following (13), the expected consumer surplus is:

$$
E C S^{*}=\alpha^{*}\left[2\left(q^{N}\right)^{2}\right]+\left(1-\alpha^{*}\right)\left[2\left(q^{C}\right)^{2}\right]=\frac{3(A+\theta)^{2}}{17} .
$$

When the non-distorting profit based fine is adopted, the expected consumer surplus amounts to:

$$
E C S_{P}=\alpha_{P}\left[2\left(q^{N}\right)^{2}\right]+\left(1-\alpha_{P}\right)\left[2\left(q^{C}\right)^{2}\right]=\frac{3(A+\theta)^{2}+28 \rho F}{17},
$$

which is obviously higher than in the benchmark case. Relevant output levels $q^{N}$ and $q^{C}$ are unaffected by the fine, which yet increases the interval region where collusion is successfully deterred $\left(\alpha_{P}>\alpha^{*}\right)$. This, in turn, reduces the probability that managers' factors discount support the collusive behaviour.

Turning to the delegation based fine, the expected consumer surplus is:

$$
\begin{aligned}
E C S_{D} & =\alpha_{D}\left[2\left(q^{N}\right)^{2}\right]+\left(1-\alpha_{D}\right)\left[2\left(q_{D}^{C}\right)^{2}\right]= \\
& =\frac{3(A+\theta)^{3}+15(A+\theta)^{2} \rho f-13(A+\theta)(\rho f)^{2}+3(\rho f)^{3}}{17(A+\theta)+3 \rho f} .
\end{aligned}
$$

\footnotetext{
${ }^{16}$ The dispute on the appropriate standard for antitrust enforcement seems still unsettled: see, for example, Pittman (2007) for more details.
} 
This is the first case where the aforementioned trade-off appears. When comparing $E C S_{D}$ with $E C S^{*}$, we have that $q_{D}^{C}<q^{C}$, as already acknowledged in Remark 1. However, collusion is less likely to occur, as $\alpha_{D}>\alpha^{*}$. Relatively simple algebraic calculations reveal that the latter effect dominates the former one, and therefore $E C S_{D}>E C S^{*}{ }^{17}$

It follows that both a profit based fine and a delegation based fine enhance the expected consumer surplus in comparison to the benchmark case, where no policy instrument was adopted. The introduction of either type of fine brings forth a deterrence effect that not only makes collusion more difficult to be sustained, but it also benefits consumers.

Under revenue equivalence, it is also possible to evaluate which one is better from a consumer's standpoint. We find that:

Proposition 3 Under (10) and assuming $\rho f<\bar{t}$, we find that $E C S_{D}>E C S_{P}^{r e}$ : a delegation based fine is always preferred by consumers in comparison to a profit based fine.

Proof see the Appendix.

The delegation based fine is not only more effective in deterring collusion, but it is also preferred by consumers. This holds despite of its distortive effect on collusive quantities. The following decomposition helps to explain why this occurs:

$$
E C S_{D}-E C S_{P}^{r e}=\underbrace{\left(\alpha_{D}-\alpha_{P}^{r e}\right)}_{\text {Deterrence effect }} \underbrace{\left[2\left(q^{N}\right)^{2}-2\left(q^{C}\right)^{2}\right]}_{>0}-\underbrace{\left(1-\alpha_{D}\right)}_{>0} \underbrace{\left[2\left(q^{C}\right)^{2}-2\left(q_{D}^{C}\right)^{2}\right]}_{\text {Expected distortionary effect }} .
$$

The difference in the expected consumer surplus under the two policy regimes can be represented by two components induced by the delegation based fine in comparison to the profit based one: a "deterrence effect" and an "expected distortionary effect". The former captures the positive effect on consumer surplus that comes from the reduction in the interval region that sustains collusion, and the corresponding increase in the output level produced. The latter represents the reduction in consumers surplus that derives from the lower output level which we obtain in presence of a delegation based fine when collusion persists.

\footnotetext{
${ }^{17}$ More precisely, $E C S_{D}-E C S^{*}=\frac{\rho f\left[246(A+\theta)^{2}-221 \rho f(A+\theta)+51(\rho f)^{2}\right]}{289(A+\theta)+51 \rho f}>0$ under the parametric restrictions imposed on $\rho f, A$, and $\theta$.
} 
The result in Proposition 3 implies that the "deterrence effect" always dominates the "expected distortionary effect". Following the basic assumptions of our paper, a delegation based fine increases the interval region where managers compete noncooperatively. In addition, although such a fine induces a loss in consumer surplus when collusion occurs, it also reduces the probability that this will happen, as a cartel is less likely to be formed.

Finally, comparative statics reveal that $\partial\left(E C S_{D}-E C S_{P}^{r e}\right) / \partial \theta>0$ : when $\theta$ increases, the delegation based fine is even more beneficial to consumers. As the power delegated to the managers are extended, the benefits of deterring the cartel further increase. The enhanced deterrence effect, by increasing the probability to obtain an even richer Cournot-Nash outcome, dominates even more the distortion generated by the delegation based instrument.

\subsection{Aggregate surplus}

Assume that the antitrust authority does not limit its attention only to consumer's protection, but it considers instead total social welfare. Following Vickers (1985), the managers' compensations linearly depends on $m$. They do not affect total welfare, as they constitute a transfer between the firms and the managers. A similar observation applies to the revenue collected by the antitrust authority, which corresponds to the expected amount paid by collusive managers. Total welfare can therefore be written as: ${ }^{18}$

$$
T W=2 \pi+2 q^{2} .
$$

where $\pi$ represents firms' profits as computed in Section 2 .

Following the same reasoning as in (13), the expected welfare in the benchmark case amounts to:

$$
E T W^{*}=\alpha^{*}\left[2 \pi^{N}+2\left(q^{N}\right)^{2}\right]+\left(1-\alpha^{*}\right)\left[2 \pi^{C}+2\left(q^{C}\right)^{2}\right]=\frac{(7 A-3 \theta)(A+\theta)}{17} .
$$

\footnotetext{
${ }^{18}$ The complete expression for total welfare is: $T W=\sum_{i=1}^{2}\left(O S_{i}\right)+\sum_{i=1}^{2}\left(M S_{i}\right)+C S+A A$, where $O S$ is the owner surplus, $M S$ the manager surplus, $C S$ the consumer surplus, and $A A$ the revenue cashed by the antitrust authority. Following the previous discussion, it is immediate to prove that this boils down to $T W=2 \pi+2 q^{2}$. Notice that the latter expression applies to all regimes, including both a profit and delegation based fine, assuming that the firms' profits in presence of a cartel is gross of both the expected fine and the managers' payment, i.e. $\pi_{i}=(p-c) q_{i}$.
} 
In the presence of a profit based fine, we find:

$$
\begin{aligned}
E T W_{P} & =\alpha_{P}\left[2 \pi^{N}+2\left(q^{N}\right)^{2}\right]+\left(1-\alpha_{P}\right)\left[2 \pi^{C}+2\left(q^{C}\right)^{2}\right]= \\
& =\frac{(7 A-3 \theta)(A+\theta)}{17}+\frac{4(5 A-7 \theta) \rho F}{17(A+\theta)} .
\end{aligned}
$$

Notice that $E T W_{P} \geq E T W^{*}$ when (5) holds. The profit based fine raises the expected welfare. The result is very intuitive: the redistributive effect that takes place when using a lump-sum transfer does not change total welfare in the two scenarios. It does increase, however, the probability to achieve the welfare enhancing Cournot-Nash outcome, as the fine shifts the threshold discount factor from $\alpha^{*}$ to $\alpha_{P}$.

Turning to the delegation based fine, the expected welfare is:

$$
\begin{aligned}
E T W_{D} & =\alpha_{D}\left[2 \pi^{N}+2\left(q^{N}\right)^{2}\right]+\left(1-\alpha_{D}\right)\left[2 \pi_{D}^{C}+2\left(q_{D}^{C}\right)^{2}\right]= \\
& =\frac{(7 A-3 \theta)(A+\theta)^{2}+(11 A-15 \theta)(A+\theta) \rho f+(A+13 \theta)(\rho f)^{2}-3(\rho f)^{3}}{17(A+\theta)+3 \rho f} .
\end{aligned}
$$

The differences with the previous case are evident: not only does the threshold discount factor increase from $\alpha^{*}$ to $\alpha_{D}$, but also the collusive welfare component $W^{C}$ is now affected by the output distortion implied by the delegation based fine.

The change in the threshold discount factor improves expected welfare, while the quantity distortion moves in the opposite direction. Algebraic calculations reveal that, under the conditions imposed in our model, the first effect always dominates the second one. The delegation based fine is therefore welfare enhancing in comparison to the benchmark case.

We can now proceed to compare the effects of the two types of fines under the assumption of revenue equivalence. The following result holds:

Proposition 4 Under (10) and assuming $\rho f<\bar{t}$, the delegation based fine increases total welfare more than a profit based fine if and only if $\rho f>\tilde{t}$, with $\tilde{t}$ increasing in $\theta$. Conversely, if $0<\rho f<\tilde{t}$, then a profit based fine is preferable.

Proof see Appendix.

Differently from the expected consumer surplus, here there is no policy instrument that always prevails for the antitrust authority. The relative benefit of a delegation based fine in comparison to a profit based fine can be written as: 


$$
\begin{aligned}
E T W_{D}-E T W_{P}^{r e}= & \underbrace{\left(\alpha_{D}-\alpha_{P}^{r e}\right)\{\underbrace{\left(2 \pi^{N}-2 \pi^{C}\right)}_{<0}+\underbrace{\left[2\left(q^{N}\right)^{2}-2\left(q^{C}\right)^{2}\right]}_{>0}\}}_{\text {Deterrence effect }} \\
& \underbrace{-\left(1-\alpha_{D}\right)\{\underbrace{\left(2 \pi^{C}-2 \pi_{D}^{C}\right)}_{\gtrless 0}+\underbrace{\left[2\left(q^{C}\right)^{2}-2\left(q_{D}^{C}\right)^{2}\right]}_{>0}\}}_{\text {Expected distortionary effect }} .
\end{aligned}
$$

By comparing (18) and (23) it is possible to understand the reason why the profit based fine can be preferred in terms of total welfare. The "deterrence effect", which remains positive, is unambiguously reduced by the component $2 \pi^{N}-2 \pi^{C}$, which indicates the loss in the profit surplus when the cartel is successfully deterred. The "expected distortionary effect", on the contrary, does not provide a clear indication on how it changes. It remains negative, but given that $2 \pi^{C}-2 \pi_{D}^{C} \gtreqless 0$, its absolute value can either increase or decrease. Algebraic calculations, however, confirm that $\left|2 \pi^{N}-2 \pi^{C}\right|>\left|2 \pi^{C}-2 \pi_{D}^{C}\right|$. The reduction in the weight of the "deterrence effect" dominates the change in the "expected distortionary effect".

The result of Proposition 4 are summarized in Figure $1 .^{19}$ The interval region in which $\tilde{t}<\rho f<\bar{t}$ represents all the combinations of expected fine $\rho f$ and delegation parameter $\theta$ for which the "deterrence effect" is still stronger than the "expected distortionary effect". The explanation is relatively simple. When the expected fine $\rho f$ is sufficiently high, the deterrence effect of a delegation based fine increases. This, in turn, reduces the relative weight of the "expected distortionary effect". Although ex post distortionary effects may increase, it is ex ante less likely that a cartel takes place. The delegation based fine is therefore preferred in terms of total welfare.

On the contrary, when $0<\rho f<\tilde{t}$, the opposite holds. For low values of the expected fine, indeed, the distortionary effect is likely to increase, as both quantities and profits are negatively affected by the delegation based fine. This stronger distortionary effect may more than compensate a weakened deterrence effect, thereby increasing the chances that the profit based fine be preferable in terms of expected total welfare.

\footnotetext{
${ }^{19}$ Remember that the intial condition that we imposed was $A \geq 2 \theta$, which verifies that equilibrium profits are non-negative in the basic model. Picture 1 has been depicted for $A=5$.
} 


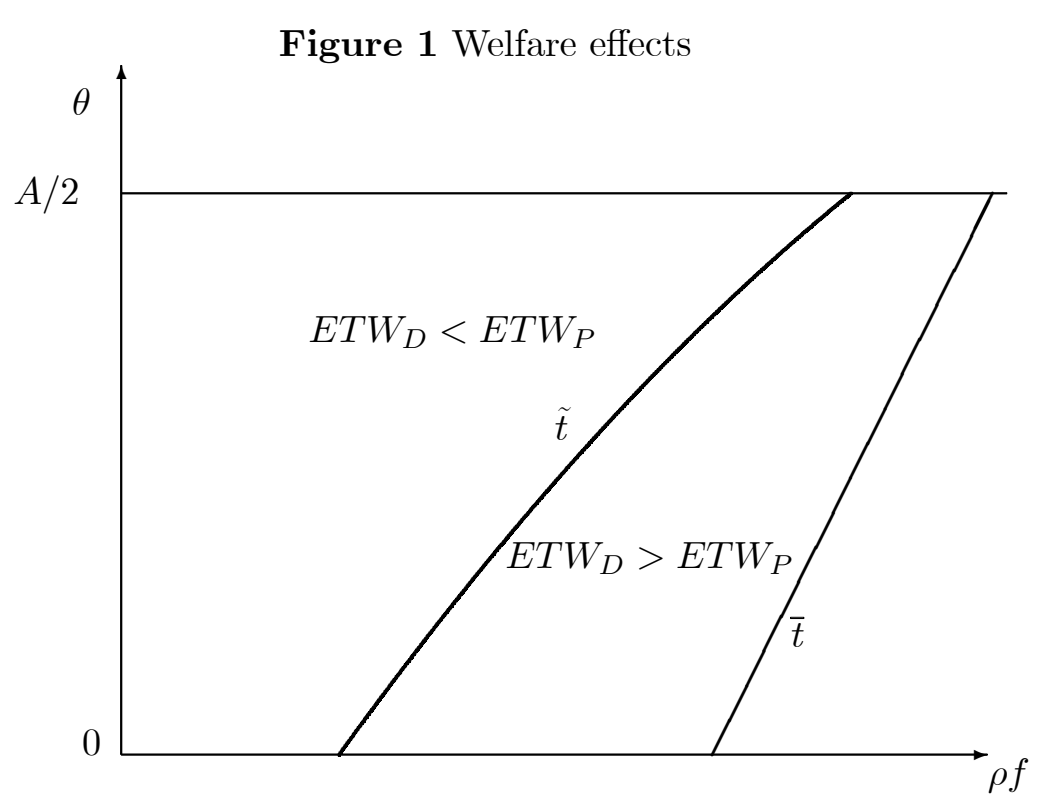

Lastly, notice that the area where $E T W_{D}>E T W_{P}^{r e}$ is decreasing in $\theta$. This appears counterintuitive, especially when compared with the consumer surplus case, where the "gain" brought by the delegation based fine was enhanced by $\theta$. However, introducing profit surplus may alter the outcome. In fact, deterring a cartel implies a decrease in profits, and such a negative effect is amplified when more powers are delegated to managers. Using (23), one can find that $\partial\left|2 \pi^{N}-2 \pi^{C}\right| / \partial \theta>$ $\partial\left|2 \pi^{C}-2 \pi_{D}^{C}\right| / \partial \theta$ : a higher $\theta$ reduces more the "deterrence effect" than the "expected distortionary effect". More in general, the negative effect of $\theta$ on profit surplus dominates its positive effect on consumer surplus, thus explaining the result.

\section{Concluding Remarks}

The fight against collusive behaviour in the US and in the EU is based on similar principles. However, substantial differences still exist, especially regarding the instruments adopted to carry out cartel deterrence. In particular, the criminal punishment of managers is perceived as a crucial deterrent in the US but not in the EU.

This paper addresses the effectiveness of different types of instruments in deterring cartels. In particular, we focus on fines levied on profits and fines targeting the powers delegated to managers. The aim is to model in a stylised way the "punish-the-firm" versus "punish-the-person" controversy and analyse its economic consequences. As 
the majority of firms involved in cartel cases are managerial firms, we analyse these two types of antitrust instruments in the context of the delegation model of Vickers (1985) and Fershtman and Judd (1987).

Our results indicate that the effectiveness of each type of instrument is closely related to the amount of powers delegated to the managers. Intuitively, a delegation based fine is more likely to effectively deter collusion when the decisional power delegated to managers is sufficiently high. If the comparison is performed under revenue equivalence, then the delegation based fine is more effective because its distortionary effect further reduces the incentives to collude in comparison to the profit based fine.

Such a distortion, however, may have a negative consequences on the overall surplus if managers are patient enough to sustain collusion, despite the antitrust efforts. In this case, we identify an important trade-off that has largely been overlooked in the existing literature between ex-ante effective deterrence and ex post output reduction if collusion takes place.

The trade-off does not arise if the antitrust authority focuses on consumer surplus as a measure of social welfare. In such a case, the delegation based fine is not only more effective in deterring cartels, but it also further expands expected welfare than the profit based fine. The same conclusion, however, does not apply if we consider total surplus. The delegation based fine erodes cartel profits more than the profit based fine, reducing the profit surplus. The interplay between the amount of the fine and the delegation parameter provides further insights on the relative weight of consumer surplus vis à vis profit effects and helps determining the overall desirability of each type of fine.

Although our results are obtained in a very stylised model, we believe that the main message of the paper can have relevant policy implications. Distortive fines maybe very tempting for antitrust authorities. They allow for more effective cartel deterrence, thereby benefiting consumers. However, if productive efficiency is also relevant, then less distortive instruments can achieve higher overall welfare by limiting the loss in profit surplus. This holds in particular for relatively low levels of the expected punishment.

Ultimately, according to the results of our welfare analysis, the choice of the best policy option may drive antitrust authorities back to the long and fierce debate about the correct welfare standard to be adopted in competition policy: consumer surplus or total welfare? 
Our work can be extended in different directions. We assumed that owners delegated a fixed amount $\theta$ to the managers. This can be relaxed to fully characterize the strategic interaction between owners and managers (see Lambertini and Trombetta, 2002). In such a context, the effectiveness of each instrument would be affected by the decisions of the owners. It can be conjectured that the most effective instrument would therefore depend on the strategic decisions of the owners at the initial stage and there could be cases in which owners can exploit managers' patience in order to bypass the efforts of the antitrust authority. Finally, leniency programs can be incorporated in our framework to study how they would interact with different types of fines and how this may affect our current results.

\section{Appendix}

\section{Proof of proposition 1}

Assume that conditions (5) and (8) hold. We compare the two threshold discount factors to obtain:

$$
\Delta \alpha=\alpha_{P}-\alpha_{D}=\frac{288}{17}\left\{\frac{\rho F}{(A+\theta)^{2}}-\frac{2 \rho f(5(A+\theta)-2 \rho f)}{[(A+\theta)+3 \rho f][17(A+\theta)+3 \rho f]}\right\}
$$

Algebraic calculations reveal that:

$$
\Delta \alpha>0 \Longleftrightarrow \rho F>\widetilde{T}=\frac{2 \rho f(A+\theta)^{2}(5(A+\theta)-2 \rho f)}{(A+\theta+3 \rho f)(17(A+\theta)+3 \rho f)},
$$

where we maintain that $\rho f<\bar{t}$. Moreover, $\widetilde{T}<T$, as it can be easily ascertained. Under condition (8), it is immediate to verify that $\widetilde{T}$ is increasing in both the expected fine $\rho f$ and the delegation parameter $\theta$ :

$$
\begin{gathered}
\frac{\partial \widetilde{T}}{\partial \rho f}=\frac{34(A+\theta)^{3}(A+\theta+\rho f)[5(A+\theta)-9 \rho f]}{(A+\theta+3 \rho f)^{2}[17(A+\theta)+3 \rho f]^{2}}>0, \\
\frac{\partial \widetilde{T}}{\partial \theta}=\frac{2(A+\theta) \rho f\left[85(A+\theta)^{3}+540(A+\theta)^{2} \rho f+27(A+\theta)(\rho f)^{2}-36(\rho f)^{3}\right]}{(A+\theta+3 \rho f)^{2}[17(A+\theta)+3 \rho f]^{2}}>0 .
\end{gathered}
$$

This completes the proof. 


\section{Proof of proposition 2}

Remember that the comparison between (??) and (9) takes place under the restriction $t<\bar{t}=[(A+\theta)(3-2 \sqrt{2})] / 3$. We obtain:

$$
\Delta \alpha^{r e}=\alpha_{P}^{r e}-\alpha_{D}=-\frac{432 \rho f}{17} \frac{3(\rho f)^{3}+15(A+\theta)(\rho f)^{2}-15(A+\theta)^{2} \rho f+(A+\theta)^{3}}{(A+\theta)^{2}(A+\theta+3 \rho f)(17 A+17 \theta+3 \rho f)} .
$$

Under the restriction imposed, the sign depends only on the term:

$$
3(\rho f)^{3}+15(A+\theta)(\rho f)^{2}-15(A+\theta)^{2} \rho f+(A+\theta)^{3} \gtreqless 0 .
$$

This term has three real and positive zeros that can not be identified but through trigonometric methods (casus irreducibilis). The relevant one is: $\widetilde{\rho f}=0.79065(A+$ $\theta)>\bar{t}$ implying that $\alpha_{P}^{r e}-\alpha_{D}<0$ for all values $0<\rho f<\bar{t}$.

\section{Proof of proposition 3}

Consider revenue equivalence as expressed in (10). The expected producer surplus resulting from the profit based fine re-writes as follows:

$$
E C S_{P}^{r e} \equiv \frac{3(A+\theta)^{2}+28 \rho f \cdot(A+\theta)-28(\rho f)^{2}}{17} .
$$

Assume that condition (11) holds. It is tedious but relatively simple to verify that

$$
E C S_{D}-E C S_{P}^{r e}=\frac{\rho f\left[8(A+\theta)^{2}-25(A+\theta) \rho f+93(\rho f)^{2}\right]}{289(A+\theta)+51 \rho f}>0 .
$$

This completes the proof.

\section{Proof of proposition 4}

The comparison is performed for $0<\rho f<\bar{t}$. The welfare differential can be written as:

$E T W_{D}-E T W_{P}^{r e}=\frac{f \rho\left(-3 f^{2} \rho^{2}(7 A+31 \theta)+f \rho(157 A+25 \theta)(A+\theta)-4(A+2 \theta)(A+\theta)^{2}\right)}{17(A+\theta)(17(A+\theta)+3 f \rho)}$. 
The sign of this expression depends on the numerator. The expression as a function of $\rho f$ has one zero that is relevant in our domain, $\rho f=\widetilde{t}(\theta)$ with

$$
\widetilde{t}(\theta)=\frac{(A+\theta)\left(157 A+25 \theta-\sqrt{24313 A^{2}+5690 A \theta-2351 \theta^{2}}\right)}{6(7 A+31 \theta)} .
$$

The sign of $\partial \widetilde{t}(\theta) / \partial \theta$ is the same than the sign of the following expression:

$563597 A^{3}+44907 A^{2} \theta-55281 A \theta^{2}+72881 \theta^{3}+\sqrt{24313 A^{2}+5690 A \theta-2351 \theta^{2}}\left(-3593 A^{2}+350 A \theta+775 \theta^{2}\right)$, which can be shown to be positive under the assumption of our paper. It follows that $\widetilde{t}(\theta)$ is increasing with $\theta$.

\section{References}

[1] Allain, M.L., Boyer, M., Kotchoni, R. and Ponsard, J.P. (2011). The determination of optimal fines in cartel cases. The myth of underdeterrence. CIRANO Working Paper.

[2] Aubert, C., Rey, P. and W. E. Kovacic (2006). The Impact of leniency and whistleblowing programs on cartels. International Journal of Industrial Organization, 24, pp. 1264-1266.

[3] Avramovich, M.C. (2010). Prosecuting Cartels: Do High Fines Always Contribute to Social Welfare? mimeo.

[4] Baumol, W.J. (1958). On the theory of oligopoly. Economica, 25, pp. 187-198.

[5] Becker, G. (1968). Crime and punishment: an economic approach. Journal of Political Economy, 76, pp. 169-217.

[6] Besanko, D. and D. Spulber (1989). Antitrust enforcement under asymmetric information. Economic Journal, 99, pp. 408-525.

[7] Buccirossi, P. and G. Spagnolo (2007). Optimal fines in the era of whistleblowers: should price fixers still go to prison? In V. Goshal and J. Stennek (Eds.): The Political Economy of Antitrust. Elsevier: North Holland.

[8] Chen, Z. and P. Rey (2012). On the design of leniency programs. IDEI Working Paper. 
[9] Craycraft, C., J.L. Craycraft, and J.C. Gallo, J.C. (1997). Antitrust sanctions and a firm's ability to pay. Review of Industrial Organization, 12, pp. 171-183.

[10] Fershtman, C. and K.L. Judd (1987). Equilibrium incentives in oligopoly. American Economic Review, 77, pp. 927-940.

[11] Friedman, J.W. (1971). A non-cooperative equilibrium for supergames. Review of Economic Studies, 38, pp. 1-12.

[12] Gallo, J.C., Dau-Schmidt, K.G., Craycraft, J.L. and C. J. Parker (1994). Criminal penalties under the Sherman Act: a study of law and economics. Research in Law and Economics, 16, pp. 25-71.

[13] Harrington, J.E. (2004). Cartel pricing dynamics in the presence of an antitrust authority. Rand Journal of Economics, 35, pp. 651-673.

[14] Harrington, J.E. (2005). Optimal cartel pricing in the presence of an antitrust authority. International Economic Review, 46, pp. 145-169.

[15] Harrington J.E. and J. Chen (2006). Cartel pricing dynamics with cost variability and endogenous buyer detection. International Journal of Industrial Organization, 24, pp. 1185-1212.

[16] Khan, A. (2012). Rethinking sanctions for breaching EU Competition Law: is director disqualification the answer? World Competition, 35(1), pp. 77-102.

[17] Lambertini, L. and M. Trombetta (2002). Delegation and firms' ability to collude. Journal of Economic Behavior and Organization, 47, pp. 359-373.

[18] Massey, P. (2004). Criminal sanctions for competition law: a review of Irish experience. The Competition Law Review, 1, pp. 23-40.

[19] Motta, M. and Polo, M. (2003). Leniency programs and cartel prosecution. International Journal of Industrial Organization, 21, pp. 347-379.

[20] Pittman, R.W. (2007). Consumer surplus as the appropriate standard for antitrust enforcement. Competition Policy International, 3, pp. 205-224.

[21] Reindl, A. P. (2006). How Strong Is the Case for Criminal Sanctions in Cartel Cases, in Criminalisation of Competition Law Enforcement: Economic and Legal 
Implications for the EU Member States, ed. K. Cseres, M. Schinkel \& F. Vogelaar (UK: Edward Elgar Publishing), pp. 110-132.

[22] Rey, P. (2003). Towards a theory of competition policy. In Advances in Economics and Econometrics: Theory and Applications - Eight World Congress. Cambridge University Press. 2 (36), 82-132.

[23] Souam, S. (2001). Optimal antitrust policy under different regimes of fines. International Journal of Industrial Organization, 19, pp. 1-26.

[24] Spagnolo, G. (2004). Divide et impera: optimal leniency programs. CEPR Working Paper No 4840.

[25] Spagnolo, G. (2005). Managerial incentives and collusive behavior. European Economic Review, 49, pp. 1501-1523.

[26] Spagnolo, G. (2008). Leniency and whistleblowers in antitrust. In Ch. 7 of P. Buccirossi (Ed.), Handbook of Antitrust Economics, MIT Press.

[27] Vickers, J. (1985). Delegation and the theory of the firm. The Economic Journal, 95, pp. 138-147.

[28] Werden, J.G. and M. J. Simon (1987). Why price fixers should go to prison. Antitrust Bulletin, 32, pp. 917-937.

[29] Wils, W.P. (2002). Does the effectiveness enforcement of Articles 81 and 82 EC require not only fines on undertakings but also individual penalties in particular imprisonment? In C. Ehlermann and I. Atanasiu (Eds), European Competition Law Annual 2002; Oxford, Hart Publishing.

[30] Wils, W.P. (2005). Is criminalisation of EU competition law the answer? World Competition, 28, pp. 117-159. 
2011/1, Oppedisano, V; Turati, G.: "What are the causes of educational inequalities and of their evolution over time in Europe? Evidence from PISA"

2011/2, Dahlberg, M; Edmark, K; Lundqvist, H.: "Ethnic diversity and preferences for redistribution "

2011/3, Canova, L.; Vaglio, A.: "Why do educated mothers matter? A model of parental help"

2011/4, Delgado, F.J.; Lago-Peñas, S.; Mayor, M.: "On the determinants of local tax rates: new evidence from Spain" 2011/5, Piolatto, A.; Schuett, F.: "A model of music piracy with popularity-dependent copying costs"

2011/6, Duch, N.; García-Estévez, J.; Parellada, M.: "Universities and regional economic growth in Spanish regions"

2011/7, Duch, N.; García-Estévez, J.: "Do universities affect firms' location decisions? Evidence from Spain"

2011/8, Dahlberg, M.; Mörk, E.: "Is there an election cycle in public employment? Separating time effects from election year effects"

2011/9, Costas-Pérez, E.; Solé-Ollé, A.; Sorribas-Navarro, P.: “Corruption scandals, press reporting, and accountability. Evidence from Spanish mayors"

2011/10, Choi, A.; Calero, J.; Escardíbul, J.O.: "Hell to touch the sky? private tutoring and academic achievement in Korea"

2011/11, Mira Godinho, M.; Cartaxo, R.: "University patenting, licensing and technology transfer: how organizational context and available resources determine performance"

2011/12, Duch-Brown, N.; García-Quevedo, J.; Montolio, D.: “The link between public support and private R\&D effort: What is the optimal subsidy?"

2011/13, Breuillé, M.L.; Duran-Vigneron, P.; Samson, A.L.: “To assemble to resemble? A study of tax disparities among French municipalities"

2011/14, McCann, P.; Ortega-Argilés, R.: "Smart specialisation, regional growth and applications to EU cohesion policy"

2011/15, Montolio, D.; Trillas, F.: "Regulatory federalism and industrial policy in broadband telecommunications"

2011/16, Pelegrín, A.; Bolancé, C.: "Offshoring and company characteristics: some evidence from the analysis of Spanish firm data"

2011/17, Lin, C.: "Give me your wired and your highly skilled: measuring the impact of immigration policy on employers and shareholders"

2011/18, Bianchini, L.; Revelli, F.: "Green polities: urban environmental performance and government popularity"

2011/19, López Real, J.: "Family reunification or point-based immigration system? The case of the U.S. and Mexico"

2011/20, Bogliacino, F.; Piva, M.; Vivarelli, M.: "The impact of R\&D on employment in Europe: a firm-level analysis"

2011/21, Tonello, M.: "Mechanisms of peer interactions between native and non-native students: rejection or integration?"

2011/22, García-Quevedo, J.; Mas-Verdú, F.; Montolio, D.: "What type of innovative firms acquire knowledge intensive services and from which suppliers?"

2011/23, Banal-Estañol, A.; Macho-Stadler, I.; Pérez-Castrillo, D.: "Research output from university-industry collaborative projects"

2011/24, Ligthart, J.E.; Van Oudheusden, P.: "In government we trust: the role of fiscal decentralization"

2011/25, Mongrain, S.; Wilson, J.D.: "Tax competition with heterogeneous capital mobility"

2011/26, Caruso, R.; Costa, J.; Ricciuti, R.: "The probability of military rule in Africa, 1970-2007"

2011/27, Solé-Ollé, A.; Viladecans-Marsal, E.: "Local spending and the housing boom"

2011/28, Simón, H.; Ramos, R.; Sanromá, E.: "Occupational mobility of immigrants in a low skilled economy. The Spanish case"

2011/29, Piolatto, A.; Trotin, G.: "Optimal tax enforcement under prospect theory"

2011/30, Montolio, D; Piolatto, A.: "Financing public education when altruistic agents have retirement concerns" 2011/31, García-Quevedo, J.; Pellegrino, G.; Vivarelli, M.: "The determinants of YICs' R\&D activity"

2011/32, Goodspeed, T.J.: "Corruption, accountability, and decentralization: theory and evidence from Mexico"

2011/33, Pedraja, F.; Cordero, J.M.: "Analysis of alternative proposals to reform the Spanish intergovernmental transfer system for municipalities"

2011/34, Jofre-Monseny, J.; Sorribas-Navarro, P.; Vázquez-Grenno, J.: "Welfare spending and ethnic heterogeneity: evidence from a massive immigration wave"

2011/35, Lyytikäinen, T.: "Tax competition among local governments: evidence from a property tax reform in Finland" 2011/36, Brülhart, M.; Schmidheiny, K.: "Estimating the Rivalness of State-Level Inward FDI"

2011/37, García-Pérez, J.I.; Hidalgo-Hidalgo, M.; Robles-Zurita, J.A.: "Does grade retention affect achievement? Some evidence from Pisa"

2011/38, Boffa, f.; Panzar. J.: "Bottleneck co-ownership as a regulatory alternative" 
2011/39, González-Val, R.; Olmo, J.: "Growth in a cross-section of cities: location, increasing returns or random growth?"

2011/40, Anesi, V.; De Donder, P.: "Voting under the threat of secession: accommodation vs. repression"

2011/41, Di Pietro, G.; Mora, T.: "The effect of the l'Aquila earthquake on labour market outcomes"

2011/42, Brueckner, J.K.; Neumark, D.: "Beaches, sunshine, and public-sector pay: theory and evidence on amenities and rent extraction by government workers"

2011/43, Cortés, D.: "Decentralization of government and contracting with the private sector"

2011/44, Turati, G.; Montolio, D.; Piacenza, M.: "Fiscal decentralisation, private school funding, and students' achievements. A tale from two Roman catholic countries"

2012

2012/1, Montolio, D.; Trujillo, E.: "What drives investment in telecommunications? The role of regulation, firms' internationalization and market knowledge"

2012/2, Giesen, K.; Suedekum, J.: "The size distribution across all "cities": a unifying approach"

2012/3, Foremny, D.; Riedel, N.: "Business taxes and the electoral cycle"

2012/4, García-Estévez, J.; Duch-Brown, N.: "Student graduation: to what extent does university expenditure matter?"

2012/5, Durán-Cabré, J.M.; Esteller-Moré, A.; Salvadori, L.: "Empirical evidence on horizontal competition in tax enforcement"

2012/6, Pickering, A.C.; Rockey, J.: "Ideology and the growth of US state government"

2012/7, Vergolini, L.; Zanini, N.: "How does aid matter? The effect of financial aid on university enrolment decisions"

2012/8, Backus, P.: "Gibrat's law and legacy for non-profit organisations: a non-parametric analysis"

2012/9, Jofre-Monseny, J.; Marín-López, R.; Viladecans-Marsal, E.: "What underlies localization and urbanization economies? Evidence from the location of new firms"

2012/10, Mantovani, A.; Vandekerckhove, J.: "The strategic interplay between bundling and merging in complementary markets"

2012/11, Garcia-López, M.A.: "Urban spatial structure, suburbanization and transportation in Barcelona"

2012/12, Revelli, F.: "Business taxation and economic performance in hierarchical government structures"

2012/13, Arqué-Castells, P.; Mohnen, P.: "Sunk costs, extensive R\&D subsidies and permanent inducement effects"

2012/14, Boffa, F.; Piolatto, A.; Ponzetto, G.: "Centralization and accountability: theory and evidence from the Clean Air Act"

2012/15, Cheshire, P.C.; Hilber, C.A.L.; Kaplanis, I.: "Land use regulation and productivity - land matters: evidence from a UK supermarket chain"

2012/16, Choi, A.; Calero, J.: "The contribution of the disabled to the attainment of the Europe 2020 strategy headline targets"

2012/17, Silva, J.I.; Vázquez-Grenno, J.: "The ins and outs of unemployment in a two-tier labor market"

2012/18, González-Val, R.; Lanaspa, L.; Sanz, F.: "New evidence on Gibrat's law for cities"

2012/19, Vázquez-Grenno, J.: "Job search methods in times of crisis: native and immigrant strategies in Spain"

2012/20, Lessmann, C.: "Regional inequality and decentralization - an empirical analysis"

2012/21, Nuevo-Chiquero, A.: "Trends in shotgun marriages: the pill, the will or the cost?"

2012/22, Piil Damm, A.: "Neighborhood quality and labor market outcomes: evidence from quasi-random neighborhood assignment of immigrants"

2012/23, Ploeckl, F.: "Space, settlements, towns: the influence of geography and market access on settlement distribution and urbanization"

2012/24, Algan, Y.; Hémet, C.; Laitin, D.: "Diversity and local public goods: a natural experiment with exogenous residential allocation"

2012/25, Martinez, D.; Sjögren, T.: "Vertical externalities with lump-sum taxes: how much difference does unemployment make?"

2012/26, Cubel, M.; Sanchez-Pages, S.: "The effect of within-group inequality in a conflict against a unitary threat"

2012/27, Andini, M.; De Blasio, G.; Duranton, G.; Strange, W.C.: "Marshallian labor market pooling: evidence from Italy"

2012/28, Solé-Ollé, A.; Viladecans-Marsal, E.: "Do political parties matter for local land use policies?"

2012/29, Buonanno, P.; Durante, R.; Prarolo, G.; Vanin, P.: "Poor institutions, rich mines: resource curse and the origins of the Sicilian mafia"

2012/30, Anghel, B.; Cabrales, A.; Carro, J.M.: "Evaluating a bilingual education program in Spain: the impact beyond foreign language learning" 
2012/31, Curto-Grau, M.; Solé-Ollé, A.; Sorribas-Navarro, P.: "Partisan targeting of inter-governmental transfers \& state interference in local elections: evidence from Spain"

2012/32, Kappeler, A.; Solé-Ollé, A.; Stephan, A.; Välilä, T.: "Does fiscal decentralization foster regional investment in productive infrastructure?"

2012/33, Rizzo, L.; Zanardi, A.: "Single vs double ballot and party coalitions: the impact on fiscal policy. Evidence from Italy"

2012/34, Ramachandran, R.: "Language use in education and primary schooling attainment: evidence from a natural experiment in Ethiopia"

2012/35, Rothstein, J.: "Teacher quality policy when supply matters"

2012/36, Ahlfeldt, G.M.: "The hidden dimensions of urbanity"

2012/37, Mora, T.; Gil, J.; Sicras-Mainar, A.: "The influence of BMI, obesity and overweight on medical costs: a panel data approach"

2012/38, Pelegrín, A.; García-Quevedo, J.: "Which firms are involved in foreign vertical integration?"

2012/39, Agasisti, T.; Longobardi, S.: "Inequality in education: can Italian disadvantaged students close the gap? A focus on resilience in the Italian school system"

2013

2013/1, Sánchez-Vidal, M.; González-Val, R.; Viladecans-Marsal, E.: "Sequential city growth in the US: does age matter?"

2013/2, Hortas Rico, M.: "Sprawl, blight and the role of urban containment policies. Evidence from US cities"

2013/3, Lampón, J.F.; Cabanelas-Lorenzo, P-; Lago-Peñas, S.: "Why firms relocate their production overseas? The answer lies inside: corporate, logistic and technological determinants"

2013/4, Montolio, D.; Planells, S.: "Does tourism boost criminal activity? Evidence from a top touristic country"

2013/5, Garcia-López, M.A.; Holl, A.; Viladecans-Marsal, E.: "Suburbanization and highways: when the Romans, the Bourbons and the first cars still shape Spanish cities"

2013/6, Bosch, N.; Espasa, M.; Montolio, D.: "Should large Spanish municipalities be financially compensated? Costs and benefits of being a capital/central municipality"

2013/7, Escardíbul, J.O.; Mora, T.: "Teacher gender and student performance in mathematics. Evidence from Catalonia"

2013/8, Arqué-Castells, P.; Viladecans-Marsal, E.: "Banking towards development: evidence from the Spanish banking expansion plan"

2013/9, Asensio, J.; Gómez-Lobo, A.; Matas, A.: "How effective are policies to reduce gasoline consumption? Evaluating a quasi-natural experiment in Spain"

2013/10, Jofre-Monseny, J.: "The effects of unemployment benefits on migration in lagging regions"

2013/11, Segarra, A.; García-Quevedo, J.; Teruel, M.: "Financial constraints and the failure of innovation projects"

2013/12, Jerrim, J.; Choi, A.: "The mathematics skills of school children: How does England compare to the high performing East Asian jurisdictions?"

2013/13, González-Val, R.; Tirado-Fabregat, D.A.; Viladecans-Marsal, E.: "Market potential and city growth: Spain 1860-1960"

2013/14, Lundqvist, H.: "Is it worth it? On the returns to holding political office"

2013/15, Ahlfeldt, G.M.; Maennig, W.: "Homevoters vs. leasevoters: a spatial analysis of airport effects"

2013/16, Lampón, J.F.; Lago-Peñas, S.: "Factors behind international relocation and changes in production geography in the European automobile components industry"

2013/17, Guío, J.M.; Choi, A.: "Evolution of the school failure risk during the 2000 decade in Spain: analysis of Pisa results with a two-level logistic mode"

2013/18, Dahlby, B.; Rodden, J.: "A political economy model of the vertical fiscal gap and vertical fiscal imbalances in a federation"

2013/19, Acacia, F.; Cubel, M.: "Strategic voting and happiness"

2013/20, Hellerstein, J.K.; Kutzbach, M.J.; Neumark, D.: "Do labor market networks have an important spatial dimension?"

2013/21, Pellegrino, G.; Savona, M.: "Is money all? Financing versus knowledge and demand constraints to innovation" 2013/22, Lin, J.: "Regional resilience"

2013/23, Costa-Campi, M.T.; Duch-Brown, N.; García-Quevedo, J.: "R\&D drivers and obstacles to innovation in the energy industry" 
2013/24, Huisman, R.; Stradnic, V.; Westgaard, S.: "Renewable energy and electricity prices: indirect empirical evidence from hydro power" 
